\title{
The Effects of an Ultra-low-Volume Application of Etofenprox for Mosquito Management on Megachile rotundata (Hymenoptera: Megachilidae) Larvae and Adults in an Agricultural Setting
}

\section{Authors: Alyssa M. Piccolomini, Michelle L. Flenniken, Kevin M. O'Neill, and Robert K. D. Peterson}

This is a pre-copyedited, author-produced PDF of an article accepted for publication in Journal of Economic Entomology following peer review. The version of record, see citation below, is available online at: https://dx.doi.org/10.1093/iee/tox343.

Piccolomini, Alyssa M. , Michelle L. Flenniken, Kevin M. Ol'Neill, and Robert K. Peterson. "The Effects of an Ultra-low-Volume Application of Etofenprox for Mosquito Management on Megachile rotundata (Hymenoptera: Megachilidae) Larvae and Adults in an Agricultural Setting." Journal of Economic Entomology 111, no. 1 (February 2018): 33-38. DOI: 10.1093/jee/tox343. 


\title{
The Effects of an Ultra-low-Volume Application of Etofenprox for Mosquito Management on Megachile rotundata (Hymenoptera: Megachilidae) Larvae and Adults in an Agricultural Setting
}

\author{
Alyssa M. Piccolomini, ${ }^{1,2}$ Michelle L. Flenniken, ${ }^{3}$ Kevin M. O’Neill, ${ }^{1}$ and \\ Robert K. D. Peterson ${ }^{1}$ \\ 'Department of Land Resources and Environmental Sciences, Montana State University, Bozeman, MT 59715, ${ }^{2}$ Corresponding \\ author, e-mail: piccolominialyssa@gmail.com, and ${ }^{3}$ Department of Plant Sciences and Plant Pathology, Montana State University, \\ Bozeman, MT 59715 \\ Received 10 August 2017; Editorial decision 17 November 2017
}

\begin{abstract}
The alfalfa leafcutting bee, Megachile rotundata F. (Hymenoptera: Megachilidae), is one of the most intensively managed solitary bees and greatly contributes to alfalfa production in both the United States and Canada. Although production of certain commodities, especially alfalfa seed, has become increasingly dependent on this species' pollination proficiency, little information is known about how $M$. rotundata is affected by insecticide exposure. To better understand the risk posed to $M$. rotundata by the increasing use of insecticides to manage mosquitoes, we conducted field experiments that directly exposed $M$. rotundata nests, adults, and larvae to a pyrethroid insecticide via a ground-based ultra-low-volume (ULV) aerosol generator. We directly targeted nest shelters with Zenivex® E20 (etofenprox) at a half-maximum rate of $0.0032 \mathrm{~kg} / \mathrm{ha}$ at dusk and then observed larval mortality, adult mortality, and the total number of completed nests for both the treated and control groups. There was no significant difference in the proportion of dead $(P=0.99)$ and alive $(P=0.23)$ larvae when the control group was compared with the treated group. We also did not observe a significant difference in the number of emerged adults reared from the treated shelters $(P=0.22$ and 0.50 for females and males, respectively), and the number of completed cells after exposure to the insecticides continued to increase throughout the summer, indicating that provisioning adults were not affected by the insecticide treatment. The results from this study suggest that the amount of insecticide reaching nest shelters may not be sufficient to cause significant mortality.
\end{abstract}

Key words: risk assessment, pollination, mosquito control, agricultural entomology

\section{Introduction}

The alfalfa leafcutting bee, Megachile rotundata F. (Hymenoptera: Megachilidae), has nearly tripled alfalfa (Medicago sativa L., Fabaceae) seed production since its introduction to the United States in the 1940s (Pitts-Singer and Cane 2011). This solitary bee has surpassed the efficiency of honey bees in the same crop, Apis mellifera L. (Hymenoptera: Apidae), primarily due to the ability of M. rotundata to trip the staminal columns of $M$. sativa as much as $80 \%$ of the time when visited, far exceeding the ability of the honey bee $(22 \%$ of visited flowers tripped) for this particular plant (Pitts-Singer and Cane 2011, Cane 2002). The capability of M. rotundata to pollinate alfalfa (as well as other crops such as canola, cranberries, and blueberries) so efficiently, as well as its coincided emergence with peak alfalfa bloom, has resulted in this species becoming the most intensively managed solitary bee in the United States, a pollinator second only to A. mellifera (Pitts-Singer and Cane 2011).
Of the $\$ 14$ billion value attributed to A. mellifera pollinated U.S. crops, $M$. rotundata pollination is responsible for one-third of that total value (Pitts-Singer 2008, Van Deynze et al. 2008, Pitts-Singer and Cane 2011). Megachile rotundata pollinates two-thirds of the world's alfalfa crop, which is primarily used to feed livestock, especially dairy cattle in the United States (Pitts-Singer 2008, Van Deynze et al. 2008, Pitts-Singer and Cane 2011).

Although $M$. rotundata is the most intensively managed solitary bee, research has primarily focused on the effect of insecticides on A. mellifera, and rarely focused on the effects on other bee species (Caron 1979, Hester et al. 2001, Rinkevich et al. 2017). Solitary bees are important pollinators of plants in wild and agricultural settings. Although they play a crucial role in both residential and commercial settings, solitary bees have been largely ignored in pesticide regulations (Blacquière et al. 2012, Sandrock et al. 2013). We, therefore, aimed to assess how pyrethroids, a commonly used insecticide class 
for the management of mosquitoes and other pest insects, affects both an existing and a future generation of $M$. rotundata.

Pyrethroids represent approximately $23 \%$ of the global insecticide market and with over 3,500 registered formulations worldwide, they are one of the most commonly used classes of insecticides today (Schleier III and Peterson 2012, USEPA 2015). For this study, we examined the effects of a formulated version of etofenprox, a nonester pyrethroid. This type of pyrethroid prolongs the opening of voltage-gated sodium channels (VGSCs) by inducing repetitive discharges (Nishimura et al. 1996), which is similar to type I pyrethroids where the VGSC is modified such that there is a slight prolongation that causes multiple long action potentials (Soderlund and Bloomquist 1989, Soderlund 2010).

A common application of these insecticides for mosquito management in both agricultural and residential settings is by ultralow-volume (ULV) aerosol generators. Sprayed formulations via ULV application tend to stay aloft in the air and therefore result in very low deposition rates of the insecticide in the surrounding environment (Lofgren et al. 1973). The average droplet size is extremely small and ranges from 8 to $30 \mu \mathrm{m}$ in diameter. Due to their small size, the droplets are capable of staying aloft in the air for prolonged periods and so be more likely to contact airborne mosquitoes. This method, in combination with pyrethroid insecticides that have a short half-life within the environment, are highly photolabile, and have a rapid knockdown effect of targeted flight mosquitoes (Crosby 1995, Schleier III and Peterson 2011), results in an efficient way to manage mosquito populations. However, the risks of these methods on solitary, nontarget, bee species are still largely unknown.

Several studies have shown that the combination of ULV application with organophosphorus and pyrethroid insecticides have detrimental effects on nontarget organisms such as honey bees, beneficial insects, and small flying insects (Hill et al. 1971, Caron et al. 1979, Jensen et al. 1999, Hester et al. 2001, Peterson et al. 2016, Rinkevich et al. 2017). However, the effect of the insecticide aerosol on $M$. rotundata nests and developing offspring is undocumented. Unlike the eusocial honey bee, M. rotundata is a solitary species in which each female separately cares for her own brood in her own individual nest cavities. Although M. rotundata is a solitary species, it is also highly gregarious and commercial nest shelters for this species consists of thousands of small cavities in which females provision nests. The different life histories compared to eusocial bees may result in dissimilar responses when exposed to insecticides. We, therefore, examined the effect of Zenivex® E20 (etofenprox) on foraging and provisioning adults and developing larvae of $M$. rotundata to observe how this insecticide affects the population when nests come in direct contact with the aerosol produced by the ULV applicator.

\section{Materials and Methods}

\section{Insects}

Diapausing $M$. rotundata larvae in loose-leaf cells were purchased from JWM Leafcutters, Inc. (Nampa, Idaho) in April 2016 and kept in cold storage until early summer to coincide with alfalfa bloom. In mid-June, bees were kept at room temperature $\left(23^{\circ} \mathrm{C}\right)$ for $3 \mathrm{~d}$ before being placed in the rearing room set to $28 \pm 2^{\circ} \mathrm{C}$, relative humidity $42-60 \%$, and a photoperiod of $16: 8$ (L:D) h; postdiapause rearing of M. rotundata at $28^{\circ} \mathrm{C}$ results in high emergence rates and adults with high lipid content (O'Neill et al. 2011). Cells of M. rotundata were placed inside Specimen Transfer Cages No-See-Um Mesh, $61 \times 61 \mathrm{~cm}$ (BioQuip Products, Inc., Rancho Dominguez, California) and reared for $10 \mathrm{~d}$, at which time, all were still pupae. The typical developmental time for $M$. rotundata from prepupal to adult is $25-30 \mathrm{~d}$ at approximately $28^{\circ} \mathrm{C}$ (O'Neill et al. 2011). We chose to develop the bees for $10 \mathrm{~d}$ to efficiently transport the loose cells from the rearing room to the field site with minimal stress. The procedure followed is roughly based on the four basic stages of management of M. rotundata bee management in the loose cell system. The four stages of this practice are: late-spring incubation, summer release and nesting, early fall removal of loose prepupal cells, and wintering of prepupal cells (Pitts-Singer 2008). We followed this protocol because it is the most common practice in production systems for M. rotundata today.

\section{Experimental Design}

Experiments were conducted in two alfalfa fields in Bozeman, Montana in the summer of 2016. The first location (Field 1) was at $45^{\circ} 42^{\prime} 50.1^{\prime \prime} \mathrm{N}, 111^{\circ} 09^{\prime} 26.6^{\prime \prime} \mathrm{W}$ and the second location (Field 2) was at $45^{\circ} 41^{\prime} 54.5^{\prime \prime} \mathrm{N}, 111^{\circ} 07^{\prime} 44.9^{\prime} \mathrm{W}$. At each location, we placed four $M$. rotundata nest shelters containing wood laminates that provided nest tunnels for the bees (Fig. 1). Two shelters at each location were treated with insecticide and two served as controls.

Each nest shelter had a total of 1,430 nest cavities available for nest construction. Female M. rotundata are capable of laying two eggs per day and may complete, under ideal conditions, as many as 57 cells over their 7- to 8-week life span when floral resources are abundant (Maeta and Kitamura 2005, Pitts-Singer and Cane 2011). Due to the average length of an individual cell, we estimated that

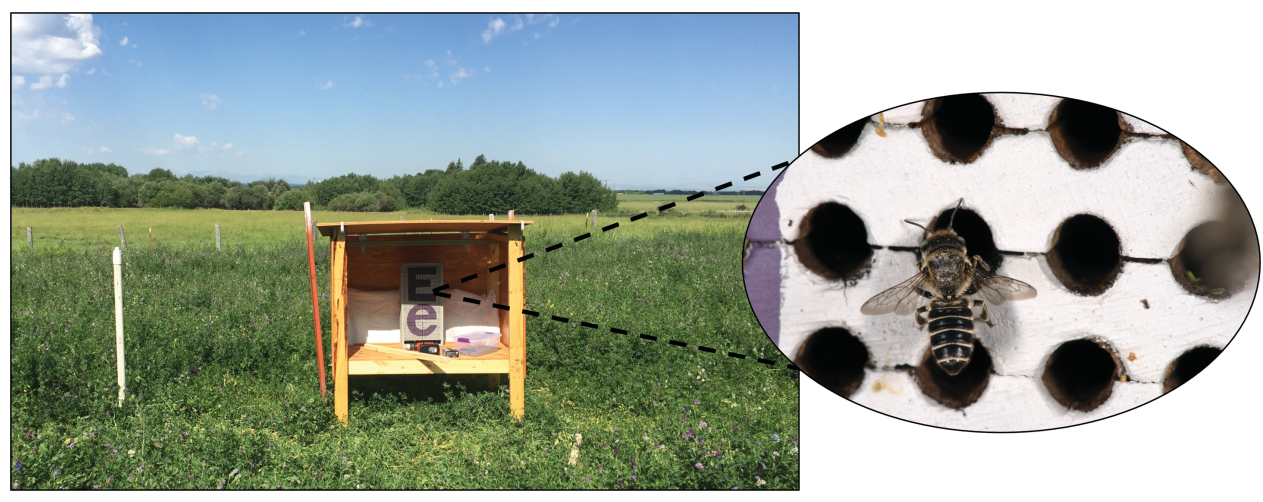

Fig. 1. Example of a nest shelter in an alfalfa plot (left) and a Megachile rotundata female entering a nest cavity (right). Each shelter consisted of approximately 1,430 cavities and a total of four nest shelters were placed at each location (eight boxes total). Shelters were $134.3 \mathrm{~cm} \times 78.1 \mathrm{~cm} \times 138.1 \mathrm{~cm}$ and were approximately $0.61 \mathrm{~m}$ off the ground. 
one row could fit 12 (actual number $8.3 \pm 0.49$ ) individual cells. One female could therefore fill approximately five tunnels with eggs over the course of her life time. As a conservative measure to maximize the number of cavities in the nest shelters that would be provisioned with next generation $M$. rotundata, we assumed one female would fill three rows throughout the summer. Based on the calculations provided by JWM Leafcutters, Inc., one gallon of loose cells was approximately 10,000 bees. The sex ratio of M. rotundata has been reported as 1:3 (female:male) (Gerber and Klostermeyer 1970, Gerber and Klostermeyer 1972), or 1:2 (females:males; Richards 1993). However, reports from JWM Leafcutters, Inc. estimates a $1: 3$ (females:males) ratio and we therefore estimated that there were 3,300 females in one gallon of loose cells, if all cells are healthy. Assuming the number of live bees per gallon, we then estimated $1.5 \mathrm{~L}$ of loose cells would be required to fill 1,430 nest rows off offspring. The $1.5 \mathrm{~L}$ of loose cells were placed within each shelter approximately $5 \mathrm{~d}$ before anticipated peak male emergence. Cells were placed in Sterlite ${ }^{\circledR} 35.9 \mathrm{~cm} \times 20 \mathrm{~cm} \times 12.4 \mathrm{~cm}$ plastic containers without lids and set out in each nest shelter. The purpose of the plastic containers was not only for transport of the loose cells, but as protection against severe weather and predators.

After 3 weeks of setting bees in the nest shelters, female M. rotundata had provisioned and filled approximately one-half of the nests in each bee board. We chose this time to apply a one-time application of Zenivex® E20 (etofenprox) directly to the shelters via a groundbased ULV applicator at the half-maximum label rate of $0.0032 \mathrm{~kg} / \mathrm{ha}$ for mosquito control and diluted at a 1:1 ratio of mineral oil (STE Oil Company, Inc., San Marcos, Texas) from a distance of $23 \mathrm{~m}$ from the opening of the nest shelter; $23 \mathrm{~m}$ is $25 \%$ of the $91 \mathrm{~m}$ effective spray swath. For this procedure, a GUARDIAN® 95 ES (Adapco, Sanford, Florida) ULV truck-mounted aerosol generator was used to make all insecticide applications. Etofenprox (2-(4-ethoxyphenyl)2-methylpropyl 3-phenoxybenzyl ether), was used as an oil-based formulation (Zenivex® E20). Zenivex ${ }^{\circledR}$ E20 was calibrated to $109.4 \mathrm{~mL} / \mathrm{min}(3.6 \mathrm{oz} / \mathrm{min})$.

Four shelters were placed at each location, $90 \mathrm{~m}$ apart from each other along a strip of alfalfa $488 \mathrm{~m}$ long and $45.7 \mathrm{~m}$ wide. Shelters were positioned to face east so that the faces of nest boards received maximum sunlight in the morning, but shade in the afternoon. Before each insecticide application, all completed (capped) nests were marked with a red grease pencil. The number of completed nest cavities was counted again when shelters were removed from the field at the end of the growing season and compared to the number just before each spray.

At each location, we randomly assigned two shelters each were randomly selected as either a control or treated shelter (four shelters total). All bees were reared and maintained within the field under the same conditions, except for application of the insecticide. The onetime application of Zenivex® E20 per each location was conducted on 26 July 2016 and 27 July 2017 at 8:57 pm and 8:14 pm MST with wind speeds of $11.4-15.1 \mathrm{kmh}^{-1}$ and $8.8-14.6 \mathrm{~km}^{-1}$ for Field 1 and Field 2, respectively. Immediately before each application, $2.4 \mathrm{~m} \times 3.6$ $\mathrm{m}$ two-layer drop cloth (Ace Hardware Corp., Oak Brook, Illinois) was placed over the front of each control shelter to ensure the insecticide application did not drift on the control shelters. The cloth coverings were removed from the control shelters within 5 min after the application. In combination with the cloth coverings, a buffer zone (area where aerosol generator was turned off) was implemented in which the drive line was 1.2 times as long as the sample line (Fig. 2) (ASAE 2013). The aerosol generator applied the insecticide approximately $23 \mathrm{~m}$ from the front of the targeted shelter. Rotating slide impingers (Leading Edge Associates, Inc., Fletcher, North Carolina) were placed $1.5 \mathrm{~m}$ from each nest shelter to verify that the insecticide entered the treated areas and did not enter the control areas. Impingers rotated $75 \times 25 \mathrm{~mm}$ Teflon-coated slides at a speed of 5.6 $\mathrm{m} / \mathrm{s}$ and were positioned $18.4 \mathrm{~cm}$ apart from center to center. After each insecticide application, slides were immediately brought back to the laboratory and inspected for the presence, number, and size of droplets using DropVision ${ }^{\circledR}$ measuring system (Leading Edge Associates, Inc., Fletcher, NC, USA; Peterson et al. 2016) (Table 1). Insecticide deposited on slides near all treated nest shelters, but not on any of the slides near the control shelters. Moreover, for each application, we observed the insecticide aerosol cloud move over the alfalfa canopy and through each treated nest shelter.

Immediately following the spray, $2.4 \mathrm{~m} \times 3.6 \mathrm{~m}$ two-layer drop cloth (Ace Hardware Corp., Oak Brook, IL) were placed directly

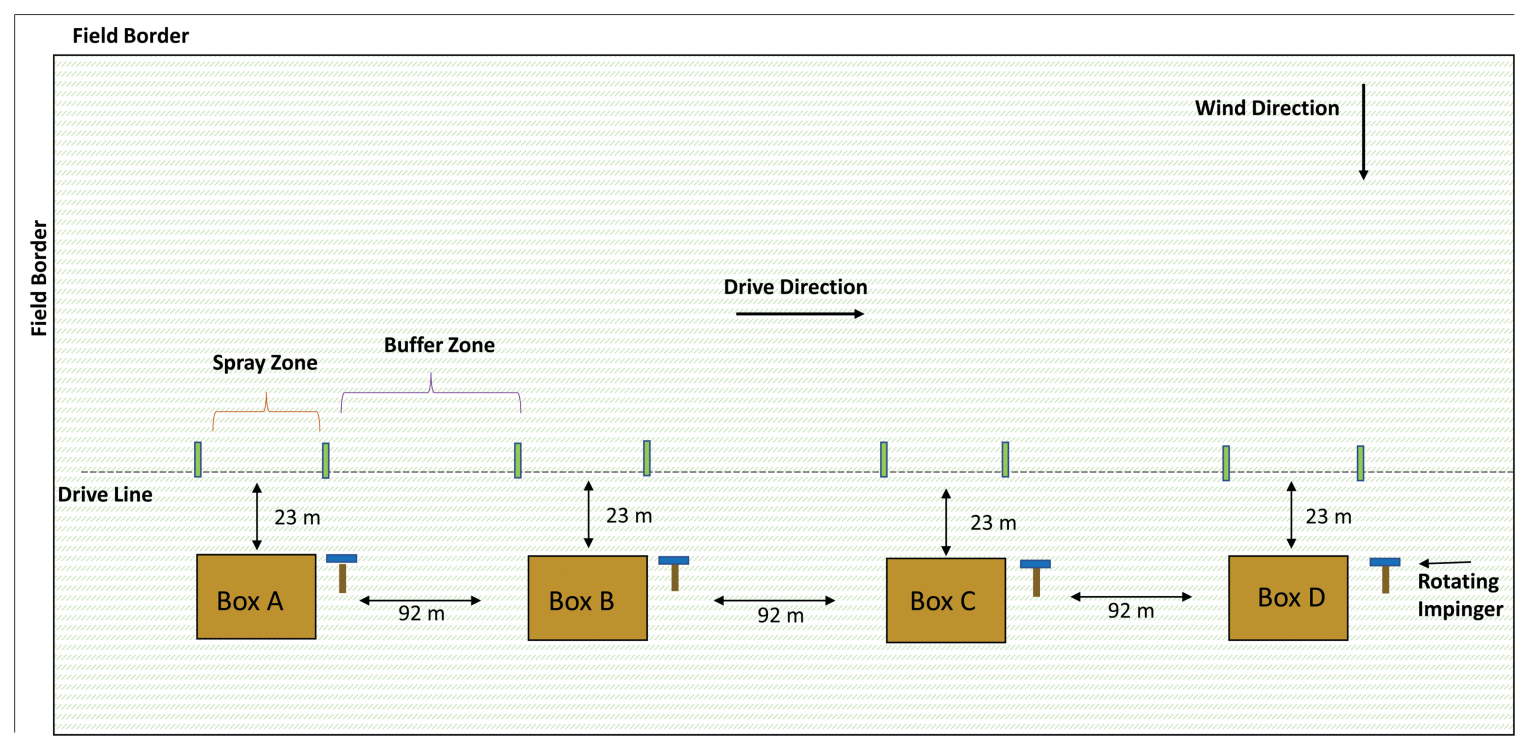

Fig. 2. Field design for an application of Zenivex ${ }^{\circledR} E 20$ (etofenprox) in an alfalfa field. The field plot was $488 \mathrm{~m}$ in length and shelters were set far enough apart to utilize the entire length of the field and to ensure there was enough distance (buffer zone) between each box to account for any insecticide spray drift. For each field, two boxes were sprayed with Zenivex® ${ }^{\circledR} 20$ at $0.003 \mathrm{~kg} / \mathrm{ha}$ at a distance of $23 \mathrm{~m}$ from each box and two boxes did not receive any treatment. 
in front of each shelter and staked to the ground to catch adults dying after application. The next morning, approximately $12 \mathrm{~h}$ later, if there were no dead bees in front of the shelter, the drop cloth was removed from the field. The purpose of the drop cloth was to potentially capture any dead adults the following $12 \mathrm{~h}$ after the insecticide application.

On 26 August 2016, nest boards were removed from the field and brought to the laboratory where they were kept at room temperature $\left(23^{\circ} \mathrm{C}\right)$. Dissection of individual leaf cells started on 28 August 2016 and continued until all 400 nest cavities (50 per box) were completed on 16 October 2016. For the dissection of individual cells, a random number generator was used to select 50 nests from each nest shelter. For control shelters, a mean of $432 \pm 18.0$ cells (1,729 total) was dissected; a mean of $452 \pm 97.5$ cells (2,260 total) from the treated shelters was dissected. We randomly selected 50 nests throughout each shelter to characterize the number of live and dead larvae in each box. The cells in each cavity were then dissected and were categorized as 1) having dead larvae killed by parasitoid wasps, 2) having dead larvae, but with cause of death "unknown", 3) have a unconsumed "pollen ball" (i.e., the presence of pollen provisions, but with no evidence of larval feeding); and "total dead", which is the sum of all dead larvae.

The remaining larvae were then stored for the winter, similar to the protocol used in the loose-cell storage system, and stored at $7^{\circ} \mathrm{C}$ for 6 months (Bohart 1962, O’Neill et al. 2011). After 6 months, leaf cells were placed in room temperature $\left(23^{\circ} \mathrm{C}\right)$ for 3 days before being placed in the rearing room set to $28 \pm 2{ }^{\circ} \mathrm{C}$, relative humidity (RH) $40-60 \%$, and a photoperiod of $16: 8$ (L:D) h; postdiapause rearing of $M$. rotundata at $28^{\circ} \mathrm{C}$ results in high emergence rates and adults with high lipid content (O'Neill et al. 2011). Cells were housed in eight Specimen Transfer Cages No-See-Um Mesh, $61 \times 61 \mathrm{~cm}$ (BioQuip Products, Inc., Rancho Dominguez, California), one cage for each shelter and reared for 15-28 d. Because some nest boxes were filled with more cells than others, a standard of $532 \mathrm{~mL}$ of cells was placed into each rearing cage $($ mean $=88.5 \mathrm{~g}, \mathrm{SE} \pm 1.9)$ from each nest shelter. Each day, newly emerged $M$. rotundata adults were removed from each cage using an aspirator, sexed, and counted so the total number emerging from each shelter was recorded.

\section{Statistical Analysis}

The proportion of larvae was recorded for each of the five categories (number alive, total dead, death due to unknown cause, death by parasitism, or presence of pollen ball without evidence of larval feeding) for each of the eight nest shelters across two fields. After determining there was no replication effect between the two field sites by performing an ANOVA on both sites and finding no statistical difference, an ANOVA test was used to compare each of the four categories against one another and then a pairwise $t$-test was used to assess the significant difference in mean proportion

Table 1. Mean droplet density ( \pm SE) of Zenivex ${ }^{\circledR}$ E20 (etofenprox) and abundance near each insecticide-treated nest shelter. Volume median diameter (VMD) of the droplets, the number of droplets collected, and the relative span factor (RSF), indicating the uniformity of the drop size distribution, are recorded for each pair of slides

\begin{tabular}{lccc}
\hline Location & VMD $(\mu \mathrm{m})(\mathrm{SE})$ & Droplets collected $(\mathrm{SE})$ & $\mathrm{RSF}(\mathrm{SE})$ \\
\hline Field 1 & $9.01(0.73)$ & $126.81(44.21)$ & $0.87(0.09)$ \\
Field 2 & $9.89(0.62)$ & $147.66(37.94)$ & $0.91(0.06)$ \\
\hline
\end{tabular}

of individuals for each treatment and for each of the four cell condition categories (R Studio, Inc. 1.0.136). Similarly, the total number of emerging bees in 2017 was compared across treatments using a Welch's $t$-Test $(\alpha=0.05)$ to account for the unequal variance between each sex and treatment. Data were log-transformed to meet the assumption of normal distribution ( $\mathrm{R}$ Studio, Inc. 1.0.136). We also compared the number of capped cells before the insecticide application to the number of capped cells at the end of the season by using a $t$-test to compare means of each treatment. All four boxes across both of the field plots were combined for this analysis.

\section{Results and Discussion}

The number of droplets and the average size of the droplets for each location provided evidence that the aerosol cloud effectively passed through the treated areas (Table 1). Thus, we can safely assume that the Zenivex®E20 contacted the nest shelters. We did not find any

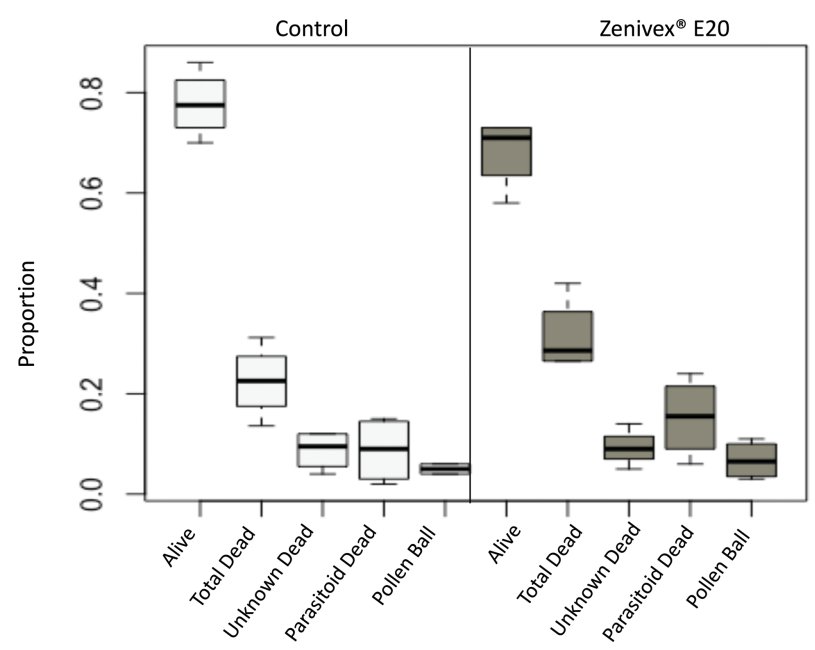

Fig. 3. Proportion of individuals present in each category for control (white) and treated (gray) (Zenivex ${ }^{\circledR}$ E20, etofenprox) groups from the total number of individuals sampled. Larvae were characterized as alive and dead (total dead). Dead larvae were categorized as "unknown dead" (dead larva, but cause unknown, "parasitoid dead" (death caused by parasitism), and "pollen ball dead" (presence of a pollen ball, but no evidence of larval feeding).

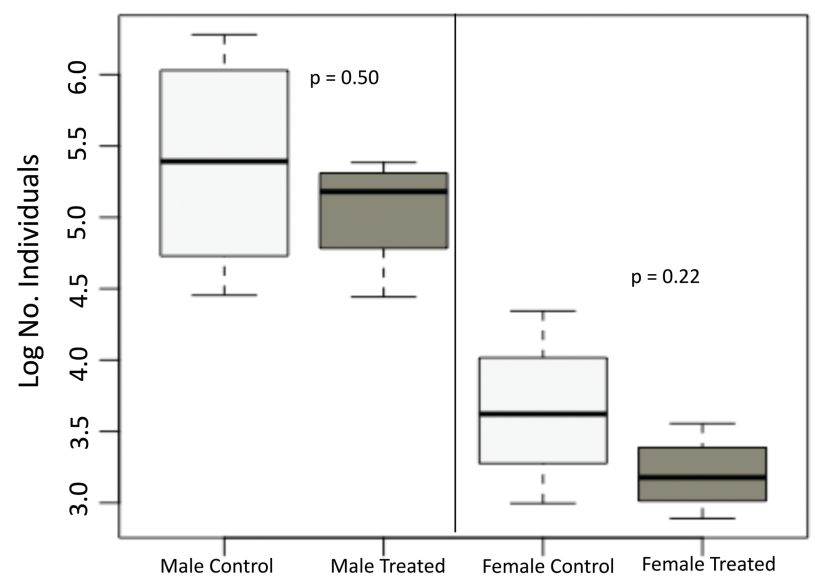

Fig. 4. Log number of adults reared from shelters exposed to Zenivex® E20 (gray) and the control group (white) from the previous growing season. 
Table 2. Cumulative number of completed nest cavities by female Megachile rotundata in 2016

\begin{tabular}{lcccc}
\hline Time of Application & Control & & Zenivex® E20 & df \\
\cline { 2 - 2 } & Total No. of Completed Cavities (SE) & & Total No. of Completed Cavities (SE) \\
\hline Before application of Zenivex® E20 & $455.5(58.90)$ & $480.0(33.54)$ & 4 \\
After application of Zenivex® E20 & $713.5(66.26)$ & $802.5(24.58)$ & 0.73 \\
\hline
\end{tabular}

evidence of droplets on the control slides and can, therefore, also assume these areas did not experience any insecticide drift.

However, despite the aerosol contacting the shelters, we found no difference between treated and control shelter in the number of live larvae, and the number of failed cells in each category (Fig. 3).

There was no statistically significant difference at the time of cell dissections in the proportion of larvae when the proportion alive, total dead, unknown dead, parasitoid dead, or pollen ball dead was compared between treatments (Fig. 3). Similarly, the number of emerged adults after winter storage did not significantly differ between treatments when compared by sex. For males, the logged mean of the control group was $5.379(\mathrm{SE}=0.405)$ and the mean of the treated group was $5.047(\mathrm{SE}=0.208 ; P=0.501)$. The logged mean of the female control group was $3.646(\mathrm{SE}=0.277)$ and the mean of the treated group was $3.20(\mathrm{SE}=0.137 ; P=0.216)$. Although there was no significant difference within each sex when compared between treatments, there was a significant difference in the total number of males and females $(P<0.001$; Fig. 4$)$. This bias in total number of emerged males and females is not treatment-related and is most likely due to male-biased sex ratio commonly observed in this species (Gerber and Klostermeyer 1970, Gerber and Klostermeyer 1972, O’Neill 2004, Sandrock et al. 2013).

We also compared the number of completed nest cavities before and after each insecticide application to better understand how provisioning adults were affected. The number of completed nest cavities the day before each application was used as a baseline when comparing the number of completed nest cavities on subsequent days (Table 2). These data were recorded to ensure boxes were still being actively filled by provisioning $M$. rotundata adult females after the insecticide application. Overall, there was an increase in nest construction in the days and weeks after the boxes were exposed to the insecticide. The lack of mortality recorded the following day after each spray and the consistent increase in cells provisions suggests that adult $M$. rotundata did not experience adverse effects after exposure.

Pyrethroids are highly toxic to bees when they are directly exposed (Torchio 1983). However, several studies have shown that when nontarget insects are not in direct contact with ULV-applied insecticides, there is often insignificant mortality between the control and treated areas (Caron 1979, Peterson et al. 2016, Rinkevich et al. 2017). In most cases, the level of direct contact is determined by the distance an application occurred from a population as well as physical barriers within a setting (Tietze et al. 1994). Hester et al. (2001) found that when the organophosphate insecticide malathion was applied using a ground-based ULV applicator for mosquito management, no significant additional adult A. mellifera mortality was observed at hives located 7.6 and $15.2 \mathrm{~m}$ from the spray source, but nearly $100 \%$ of the mosquito population died. In our study, the nest shelters were $23 \mathrm{~m}$ from the spray source, which is $25 \%$ of the effective spray swath of $91 \mathrm{~m}$.

Similarly, multiple studies have shown that when nontarget insects are directly blocked by obstacles from receiving the insecticide aerosol during application, there is little to no mortality (Caron 1979, Hester et al. 2001, Peterson et al. 2016, Rinkevich et al. 2017).
Mortality of nontarget species that do not come in direct contact with the airborne insecticide is likely mitigated due to the rapid breakdown of pyrethroids within environments as well as minimal deposition of droplets from ULV applicators within the $91 \mathrm{~m}$ spray swath (Knepper et al. 1996). Some studies have found evidence that insecticide residues may contaminate pollen and leaf foliage if insecticides are repeatedly deposited and consequently result in larval mortality (Zhu et al. 2014). However, we did not observe a significant difference between the control and treated groups throughout the growing season, suggesting that the application did not affect population numbers. Although we did not directly test for the concentration of insecticides in the pollen fed to larvae exposed to Zenivex® E20, we did not observe any significant mortality between larvae in the control group compared with larvae in the treated group and there was no significant difference in the total number of adults emerging after the winter storage period. However, future studies should also measure possible sublethal effects on larvae that carry over into adults of the next season and effect their foraging and reproductive activities.

Overall, our results indicate that there were no detectable deleterious effects on $M$. rotundata when exposed to an application of Zenivex ${ }^{\circledR}$ E20 for adult mosquito management in a field setting during active foraging and nest provisioning. The risks may be further reduced by ensuring that no nest shelters are within spray swaths, which can be relatively easy to manage by turning off aerosol generators as they pass areas of active $M$. rotundata production.

Traditionally, only A. mellifera has been intensively studied as a nontarget insect for purposes of pesticide regulation. However, this might not be the best choice for a surrogate species due to its complex eusocial life history (Arena and Sgolastra 2014, Hardstone and Scott 2010). Megachile rotundata possibly could serve as a model species for other solitary bees, or at least provide evidence that a wider variety of species is needed to more completely comprehend how insecticides affect nontarget species. Our results support the need to study more bee species to more fully understand how different insecticides used in diverse ways affect species at various points throughout their life cycle.

\section{Acknowledgments}

We thank members of the MSU CoBRA Lab: G. Sinrud for her help in analyzing droplet data and experimental setup, C. Donahoo for her assistance in data collection and experimental setup, C. Brown and D. Reis for their help with experimental setup, and C. Preftakes for assistance with aerosol generator troubleshooting and experimental setup. We thank C. Delphia for her input with experimental design and data collection and R. O'Neill for design of the nest shelters and assistance with experimental design. We also thank JWM Leafcutters, Inc. for providing the test bees and J. and S. Wold for providing the bee board laminates. A special thanks to M. Gaffke and R. Boss for allowing us to use their property as research sites, and J. Stroud (Adapco) and D. Gaiser (Central Life Sciences) for calibration of the aerosol generator and donation of Zenivex® E20. This research was funded by the Mosquito Research Foundation, the Montana Agriculture Experiment Station, and Montana State University. This material is based on work that is supported by the National Institute of Food and Agriculture, Hatch Multistate Project No. W-3045. 


\section{References Cited}

Alburaki, M., S J. Steckel, D. Chen, E. McDermott, M. Weiss, J. A. Skinner, H. Kelley, , G. Lorenz, D. R. Trapy, W.G. Meikle. et al. 2017. Landscape and pesticide effects on honey bees: forager survival and expression of acetylcholinesterase and brain oxidative genes. Apidologie. doi: 10.1007/ s13592-017-0497-3

Arena, M., and F. Sgolastra. 2014. A meta-analysis comparing the sensitivity of bees to pesticides. Ecotoxicology. 23: 324-334.

ASAE. 2013. Procedure for measuring drift deposits from ground, orchard, and aerial sprayers. American Society of Agricultural and Biological Engineers. ASAE S561.1, St. Joseph, MI, USA.

Blacquière, T., G. Smagghe, C.A. van Gestel, and V. Mommaerts. 2012. Neonicotinoids in bees: a review on concentrations, side-effects and risk assessment. Ecotoxicology. 21: 973-992.

Bohart, G. E. 1962. How to manage the alfalfa-leaf-cutting bee (Megachile rotundata Fabr.) for alfalfa pollination. Utah Agriculture Experiment Station. 144: 7.

Cane, J. H. 2002. Pollinating bees (Hymenoptera: Apiformes) of U.S. alfalfa compared for rates of pod and seed set. J. Econ. Entomol. 95: 22-27.

Caron, D. M. 1979. Effects of some ULV mosquito abatement insecticides on honey bees. J. Econ. Entomol.72: 148-151.

Crosby, D.G. 1995. Pyrethrum Flowers: Production, Chemistry, Toxicology, and Uses. ed. J. E. Casida and G. B. Quistad, Oxford University Press, New York, NY.

Gerber, H. S., and E. C. Klostermeyer. 1970. Sex control by bees: a voluntary act of egg fertilization during oviposition. Science. 167: 82-84.

Gerber, H. S., and E. C. Klostermeyer. 1972. Factors affecting the sex ratio and nesting behavior of the alfalfa leafcutter bee. Wash. Agric. Exp. Stn. Tech. Bull. 73:1-11.

Hardstone, M. C., and J. G. Scott. 2010. Is Apis mellifera more sensitive to insecticides than other insects? Pest Manag. Sci. 66: 1171-1180.

Hester, P. G., K. R. Shaffer, N. S. Tietze, H. Zhong, and N. L. Griggs, Jr. 2001. Efficacy of ground-applied ultra-low-volume malathion on honey bee survival and productivity in open and forest areas. J. Am. Mosq. Control Assoc. 17: 2-7.

Hill, E. F., D. A. Eliason, and J. W. Kilpatrick. 1971. Effects of ultra-low volume applications of malathion in Hale County, Texas. 3. Effect on nontarget animals. J. Med. Entomol. 8: 173-179.

Jensen, T., S. P. Lawler, and D. A. Dritz. 1999. Effects of ultra-low volume pyrethrin, malathion, and permethrin on nontarget invertebrates, sentinel mosquitoes, and mosquitofish in seasonally impounded wetlands. J. Am. Mosq. Control Assoc. 15: 330-338.

Knepper, R. G., E. D. Walker, S. A. Wagner, M. A. Kamrin, and M. J. Zabik. 1996. Deposition of malathion and permethrin on sod grass after single, ultra-low volume applications in a suburban neighborhood in Michigan. J. Am. Mosq. Control Assoc. 12: 45-51.

Lofgren, C. S., D. W. Anthony, and G. A. Mount. 1973. Size of aerosol droplets impinging on mosquitoes as determined with a scanning electron microscope. J. Econ. Entomol. 66: 1085-1088.

Maeta, Y., and Kitamura, T. 2005. On the number of eggs laid by one individual female in the alfalfa leaf-cutting bee, Megachile (Eutricharaea) rotundata (Fabricius) (Hymenoptera, Megachilidae). Chugoku Kontyu 19: 39-43.

Nishimura, K., H. Okimoto, T. Ueno, S. Shiraishi, K. Kodaka, and K. Tomoda. 1996. Comparison of acaricidal, insecticidal, and nerve activities of halfenprox (MTI-732) and related compounds. J. Pestic. Sci. 21: 311-316.
O’Neill, K. M., R. P. O’Neill, W. P. Kemp, and C. M. Delphia. 2011. Effect of temperature on post-wintering development and total lipid content of alfalfa leafcutting bees. Environ. Entomol. 40: 917-930.

O'Neill, R. P. 2004. Seasonal and spatial patterns of mortality and sex ratio in the alfalfa leafcutting bee, Megachile rotundata (F.). Master's thesis, Montana State University Library, Bozeman, MT, USA.

Peterson, R. K. D., C. J. Pretakes, J. L. Bodin, C. R. Brown, A. M. Piccolomini, and J. J. Schleier. 2016. Determinants of acute mortality of Hippodamia convergens (Colepotera: Coccinellidae) to ultra-low volume permethrin used for mosquito management. PeerJ. 4:e2167

Pitts-Singer, T. L. 2008. Past and present management of alfalfa bees. In R. R. James and T. L. Pitts-Singer (eds.), Bee Pollination in Agricultureal Ecosystems, vol. 7, pp. 105-123. Oxford Univ. Press, New York, 232. (https://digitalcommons.usu.edu/piru_pubs/455/).

Pitts-Singer, T. L., and J. H. Cane. 2011. The alfalfa leafcutting bee, Megachile rotundata: the world's most intensively managed solitary bee. Annu. Rev. Entomol. 56: 221-237.

Richards, K. W. 1993. Non-Apis bees as crop pollinators. Rev. Suisse. Zool. 100: 807-822.

Rinkevich, F. D., J. W. Margotta, V. Pokhrel, T. W. Walker, R. H. Vaeth, W.C. Hoffman, B. K. Fritz, R. G. Danka, T. E. Rinderer, R. L. Aldridge, et al. 2017. Limited impacts of truck-based ultra-low-volume applications of mosquito adulticides on mortality in honey bees (Apis mellifera). Bull. Entomol. Res. doi:10.1017/S0074835317000347

Sandrock, C., L. G. Tanadini, J. S. Pettis, J. C. Biesmeijer, S. G. Potts, and P. Neumann. 2013. Sublethal neonicotinoid insecticide exposure reduces solitary bee reproductive success. Agricultrual and Forest Entomology 16: 119-128.

Schleier, J. J. III, and R. K. D. Peterson. 2011. Pyrethrins and pyrethroid insecticides, pp. 94-131. In Green Trends in Insect Control. Royal Society of Chemistry, London.

Schleier, J. J. III, and R. K. D. Peterson. 2012. The joint toxicity of type I, type II, and nonester pyrethroid insecticides. J. Econ. Entomol. 105: 85-91.

Soderlund, D. M. 2010. State-dependent modification of voltage-gated sodium channels by pyrethroids. Pestic. Biochem. Physiol. 97: 78-86.

Soderlund, D. M., and J. R. Bloomquist. 1989. Neurotoxic actions of pyrethroid insecticides. Annu. Rev. Entomol. 34: 77-96.

Tietze, N. S., P. G. Hester, and K. R. Shaffer. 1994. Mass recovery of malathion in simulated open field mosquito adulticide tests. Arch. Environ. Contam. Toxicol. 26: 473-477.

Torchio, P. F. 1983. The effects of field applications of naled and trichlorfon on the alfalfa leafcutting bee, Megachile rotundata (Fabricius). J. Kans. Entomol. Soc. 56: 62-68.

United States Environmental Protection Agency (USEPA). 2015. Pyrethroids and pyrethrins. http://www.epa.gov/oppsrrd1/reevaluation/pyrethroidspyrethrins.html.

Van Deynze, A. E., S. M. Fitzpatrick, B. Hammon, M. H. McCaslin, and D. H. Putnam. 2008. Gene flow in alfalfa: biology, mitigation, and potential impact on production. CAST Spec. Publ. 28. Counc. Agric. Sci. Technol., Ames, IA. 30.

Zhu, W., D. R. Schmehl, C. A. Mullin, and J. L. Frazier. 2014. Four common pesticides, their mixtures and formulation solvent in the hive environment have high oral toxicity to honey bee larvae. PLoS One. doi: 10.1371/journal.pone. 0077547 